\title{
Combination therapy with Gamma Knife radiosurgery and antisense EGFR for malignant glioma in vitro and orthotopic xenografts
}

\author{
YANHE LI $^{1 *}$, QIANG JIA ${ }^{1 *}$, JUNXIA ZHANG ${ }^{2}$, LEI HAN ${ }^{2}$, DESHENG XU ${ }^{1}$, ANLING ZHANG $^{2}$, \\ YIPEI ZHANG ${ }^{1}$, ZHIYUAN ZHANG ${ }^{1}$, PEIYU PU ${ }^{2}$ and CHUNSHENG KANG $^{2}$ \\ ${ }^{1}$ Department of Neurosurgery and Gamma Knife Center, Tianjin Medical University 2nd Hospital, \\ Tianjin 300211; ${ }^{2}$ Department of Neurosurgery, Tianjin Medical University General Hospital and \\ Laboratory of Neuro-Oncology, Tianjin Neurological Institute, Tianjin 300052, P.R. China
}

Received December 18, 2009; Accepted March 8, 2010

DOI: 10.3892/or_00000799

\begin{abstract}
Accumulating evidence has indicated that epidermal growth factor receptor (EGFR) signaling pathway plays a potentially important role in mediating radiation resistance in human gliomas. In this study, we aimed to evaluate the effect of combination therapy with Gamma Knife radiosurgery (GKR) and antisense EGFR for malignant glioma in vitro and orthotopic xenografts. GKR and down-regulation of EGFR expression by antisense EGFR resulted in significant suppression of cell proliferation and induction of cell apoptosis in vitro. Moreover, the growth of the C6 glioma in orthotopic xenografts was significantly inhibited by this combination treatment. Thus, our results indicate that downregulation of EGFR expression enhanced the radiosensitivity of glioma and GKR in combination with antisense EGFR is a potential strategy for glioma therapy.
\end{abstract}

\section{Introduction}

Malignant gliomas, the most common primary brain tumors in adults, are characterized by aggressive and invassive growth. The natural history of untreated glioblastoma multiforme results in a median survival of 3 months (1). Despite advances

Correspondence to: Dr Desheng Xu, Department of Neurosurgery and Gamma Knife Center, Tianjin Medical University 2nd Hospital, 23 Pingjiang Road, Hexi District, Tianjin 300211, P.R. China

E-mail: tjxudesheng@163.com

Dr Chun-sheng Kang, Department of Neurosurgery, Tianjin Medical University General Hospital and Laboratory of NeuroOncology, Tianjin Neurological Institute, 154 An-Shan Road, Heping District, Tianjin 300052, P.R. China

E-mail: kang97061@yahoo.com

*Contributed equally

Key words: glioma, Gamma Knife radiosurgery, epidermal growth factor receptor, antisense, combination therapy in surgery, radiation and chemotherapy, the prognosis for patients with malignant glioma remains poor. Therefore, there is an urgent need to develop new therapeutic strategies for malignant glioma.

Gamma Knife radiosurgery (GKR), developed by Dr Lars Leksell in the late 1960 s, has become an indispensable neurosurgical tool that is used for the primary or adjuvant treatment of glioma (2). GKR differs from radiation therapy in that it is not based on variable tissue response to fractionated radiation. Instead, GKR delivers a high dose of radiation in a single session to a stereotactically defined target by converging multiple beams of ionizing radiation. By creating a rapid radiation dose fall-off around the target, radiation can be targeted to the lesion itself, and damage to surrounding structures can be minimized. Previous studies have demonstrated that radioresistance of glioma is associated with overexpression of EGFR or EGFRvIII and radiation-induced ralease of $\mathrm{TGF} \alpha$ activates the EGFR and MAPK pathway, leading to increased proliferation and protection from radiation-induced cell death (3-5). The amplification, overexpression or mutation of EGFR is the early and major molecular event in many human tumors. Our previous and other studies have also indicated that EGFR was overexpressed in malignant glioma $(6,7)$. Targeting EGFR through antisense RNA, RNA interference and specific tyrosine kinase inhibitors could inhibit significantly cell proliferation of malignant glioma in vitro and in vivo (8-11).

In the current study, we explored the effect of combination therapy with GKR and antisense EGFR on glioma growth. We used rat C6 and human TJ905 glioma cells following combined GKR and antisense EGFR treatment in vitro. A tumor intracerebral model of C6 cells for glioma was also employed to investigate the treatment effect in vivo. Our data showed that using this approach could inhibit glioma growth in vitro and orthotopic xenografts.

\section{Materials and methods}

Cell line and plasmid. Rat C6 glioma cells were obtained from the Institute of Biochemistry and Cell Biology, Chinese Academy of Sciences. Human TJ905 glioblastoma cells were 
established and characterized in the Neuro-oncology laboratory, Tianjin Neurological Institute (12). C6 cells and TJ905 cells were cultured in Dulbecco's modified Eagle's medium (DMEM) supplemented with $10 \%$ fetal calf serum at $37^{\circ} \mathrm{C}$ in $5 \% \mathrm{CO}_{2}$. The EGFR cDNA in plasmid pactQsR3 was kindly provided by Dr Laura Beguinot, Italy (13). The antisense orientation of EGFR cDNA fragment (552 bp), complementary to the 3'-coding region of EGFR mRNA, was double digested

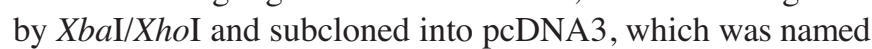
as panti-EGFR.

Antisense-EGFR transduction. For gene transfection, $2 \times 10^{5}$ cells per well were planted into six-well plates and grown overnight until they were $50-80 \%$ confluent. Plasmids pantiEGFR ( $2 \mu \mathrm{g}$ each) were transfected into C6 and TJ905 cells with lipofectamine according to the protocol. Stably resistant cells were selected using G418 as previously described (10). The panti-EGFR transfected clones were selected and expanded as cell pools for further studies.

Western blot analysis. Total protein lysates (40 $\mu \mathrm{g} / \mathrm{sample})$, were separated by SDS-PAGE. The separate proteins were transferred to PVDF membranes (Millipore, USA). The blot was incubated with primary antibody against EGFR (1:500 dilution, Santa Cruz Biotechnology), followed by incubation with HRP-conjugated secondary antibody (1:1000 dilution). The specific protein was detected using a Super signal protein detection kit (Pierce, USA). After washing with stripping buffer, the PVDF membrane was reprobed with antibody against $\beta$-actin (1:500 dilution, Santa Cruz Biotechnology).

GKR for glioma cells in vitro. The transfected or control cells $\left(4 \times 10^{7}\right)$ were planted and grown overnight in a $10-\mathrm{cm}$ Petri dish. Cells in the log phase of growth were harvested, put into Eppendof tube $\left(4 \times 10^{6} / \mathrm{ml}\right)$, centrifuged (500 x g, $\left.2 \mathrm{~min}\right)$, and then fixed to the Leksell G stereotactic frame for GKR. High-resolution MR images were obtained. Leksell Gamma Plan software (versions 5.31) was used to attain target localization for the radiosurgery (Fig. 1). A margin dose of 15 Gy was delivered to the $75 \%$ isodose line using a $4-\mathrm{mm}$ collimator of the 201 -source ${ }^{60} \mathrm{Co}$ gamma unit. Radiosurgery was performed in the Leksell gamma knife unit. After radiosurgery, cells were cultured quickly in DMEM supplemented with $10 \%$ fetal calf serum. Cell proliferation and apoptosis were detected $48 \mathrm{~h}$ post-radiosurgery by MTT, immunohistochemical and TUNEL assay, respectively.

MTT assay. Cells growth inhibition was evaluated using the MTT assay. Briefly, cells $\left(4 \times 10^{3}\right.$ per well) were plated in 96well plates and grown overnight. Each day of the consecutive 6 days, $20 \mu 1$ of MTT ( $5 \mathrm{mg} / \mathrm{ml}$, Sigma) was added to each well, and the cells were incubated at $37^{\circ} \mathrm{C}$ for an additional $4 \mathrm{~h}$. The reaction was stopped by lysing the cells with $200 \mu \mathrm{l}$ of DMSO for $5 \mathrm{~min}$. Quantitation was obtained at wavelength of $570 \mathrm{~nm}$ and expressed as a percentage of control. The data are presented as the mean $\pm \mathrm{SD}$, derived from triplicate samples of at least three independent experiments.

Antitumor activity of GKR and antisense EGFR in vivo. Adult male Sprague-Dawley rats weighing between 150 and $200 \mathrm{~g}$ each were purchased from the animal center of the Cancer
Institute of Chinese Academy of Medical Sciences. The guidelines for animal welfare were approved by the Ethics Committee on Animal Research of Tianjin Medical University. Sixty-four rats were anesthetized by an intraperitoneal injection of $10 \%$ chloral hydrate $(300 \mathrm{mg} / \mathrm{kg})$, and then placed in a stereotactic apparatus. C6 cells $\left(1 \times 10^{6}\right)$ in $10 \mu 1$ serum-free DMEM were injected into the right frontal lobe of rat using a guide-screw system implanted within the skull as described previously (14). As the tumor formation demonstrated in MRI on day 6 post-implantation, all rats were divided randomly into four groups: control group, As-EGFR group, GKR group and combined group.

Control group: $10 \mu \mathrm{l}$ PBS was injected into the tumor site by using the same coordinates with stereotactic guidance on day 6 and 8 post-implantation, respectively. As-EGFR group: $2 \mu \mathrm{g}$ of plasmids panti-EGFR mixed with $10 \mu 1$ lipofectamine were injected into the tumor site by using the same coordinates with stereotactic guidance on day 6 and 8 postimplantation, respectively. GKR group: Radiosurgery was performed in the Leksell Gamma Knife unit on day 10 postimplantation. High-resolution MR images were obtained. Leksell Gamma Plan software was used to attain target localization for the radiosurgery (Fig. 1). A margin dose of 15 Gy was delivered to the $50 \%$ isodose line using a $4-\mathrm{mm}$ collimator of the 201-source ${ }^{60} \mathrm{Co}$ gamma unit.

Combined group: $2 \mu \mathrm{g}$ of plasmids panti-EGFR mixed with $10 \mu 1$ lipofectamine were injected into the tumor site on day 6 and 8 post-implantation, and radiosurgery was performed with a margin dose of 15 Gy on day 10 post-implantation. Two days after GKR, six rats of each group were euthanized, and brains were removed for proliferation (PCNA) and apoptosis (TUNEL) examination. The other ten rats were observed for the survival period and MR images until 8 weeks post-radiosurgery. After 8 weeks, all the rats were sacrificed, and then we performed a survival period analysis.

Immunohistochemical analysis. Cell proliferation was evaluated by PCNA immunostaining using ABC-peroxidase method. Briefly, the sections were incubated with primary PCNA antibody (1:100 dilution, Santa Cruz Biotechnology) overnight at $4^{\circ} \mathrm{C}$, then incubated with a biotinylated secondary antibody (1:200 dilution) at room temperature for $1 \mathrm{~h}$, followed by the incubation with ABC-peroxidase reagent (1:200 dilution, Vector, USA) for an additional $1 \mathrm{~h}$. After washing with Tris-buffer, the sections were stained with DAB (3,3 diaminobenzidine, $30 \mathrm{mg}$ dissolved in $100 \mathrm{ml}$ Trisbuffer containing $0.03 \% \mathrm{H}_{2} \mathrm{O}_{2}$ ) for $5 \mathrm{~min}$, rinsed in water and counterstained with hematoxylin. The percentage of the positive staining cells in a total number of 500-1000 cells was determined under x400 magnification by a light microscope. Apoptosis was detected by TUNEL method using in situ cell death kit (Boehringer Mannheim, Germany) according to the supplier's instructions. Apoptotic Index (AI) was calculated as the number of apoptotic cells per 500-1000 total cells counted under the $\mathrm{x} 400$ magnification by a light microscope.

Statistical analysis. The data obtained in this study were analyzed by one way ANOVA test and t-test using SPSS 11.0 software. Survival was analyzed by a log-rank test based on the Kaplan-Meier test. $\mathrm{P}<0.05$ was considered as significant. 


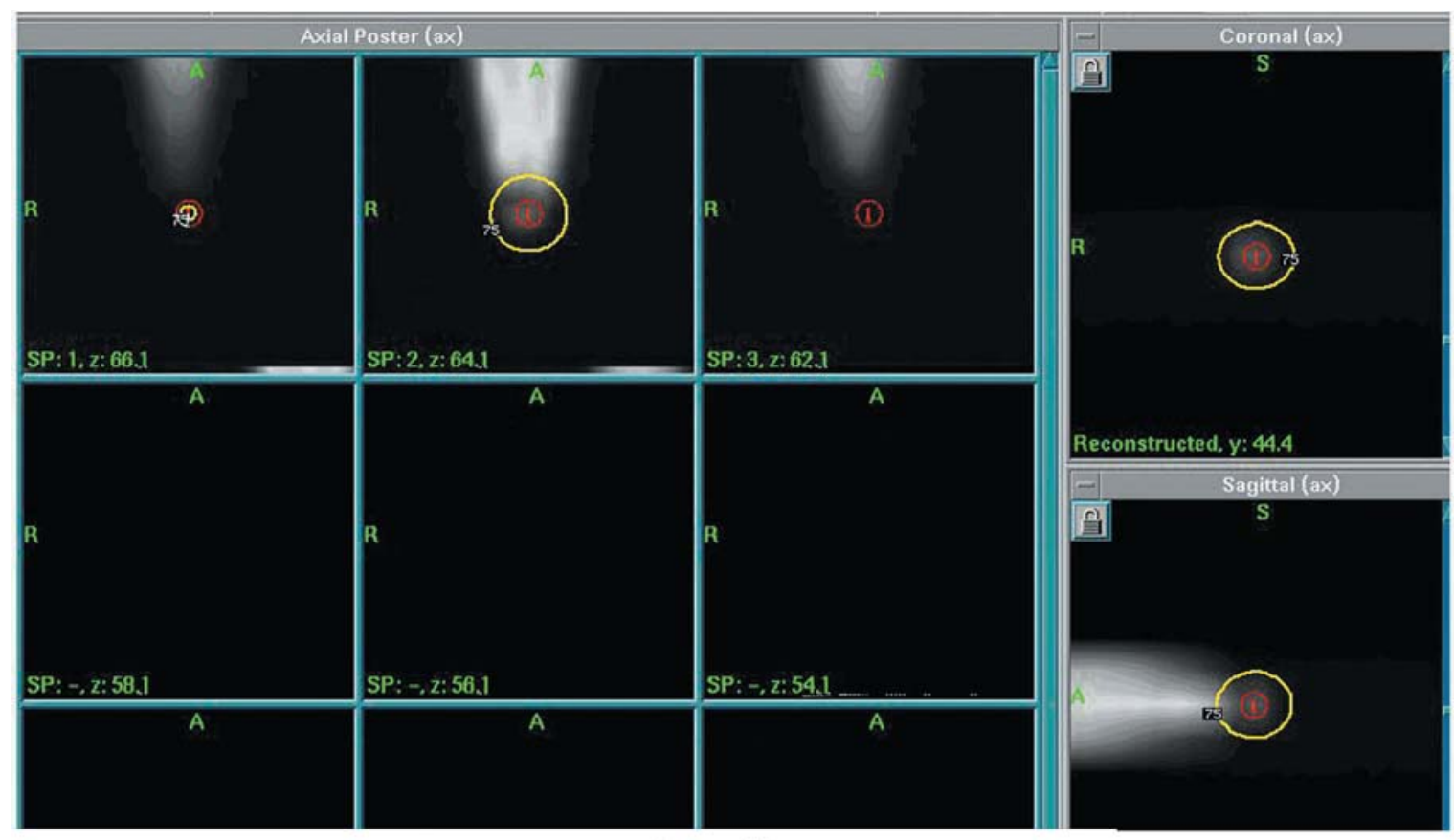

in vitro

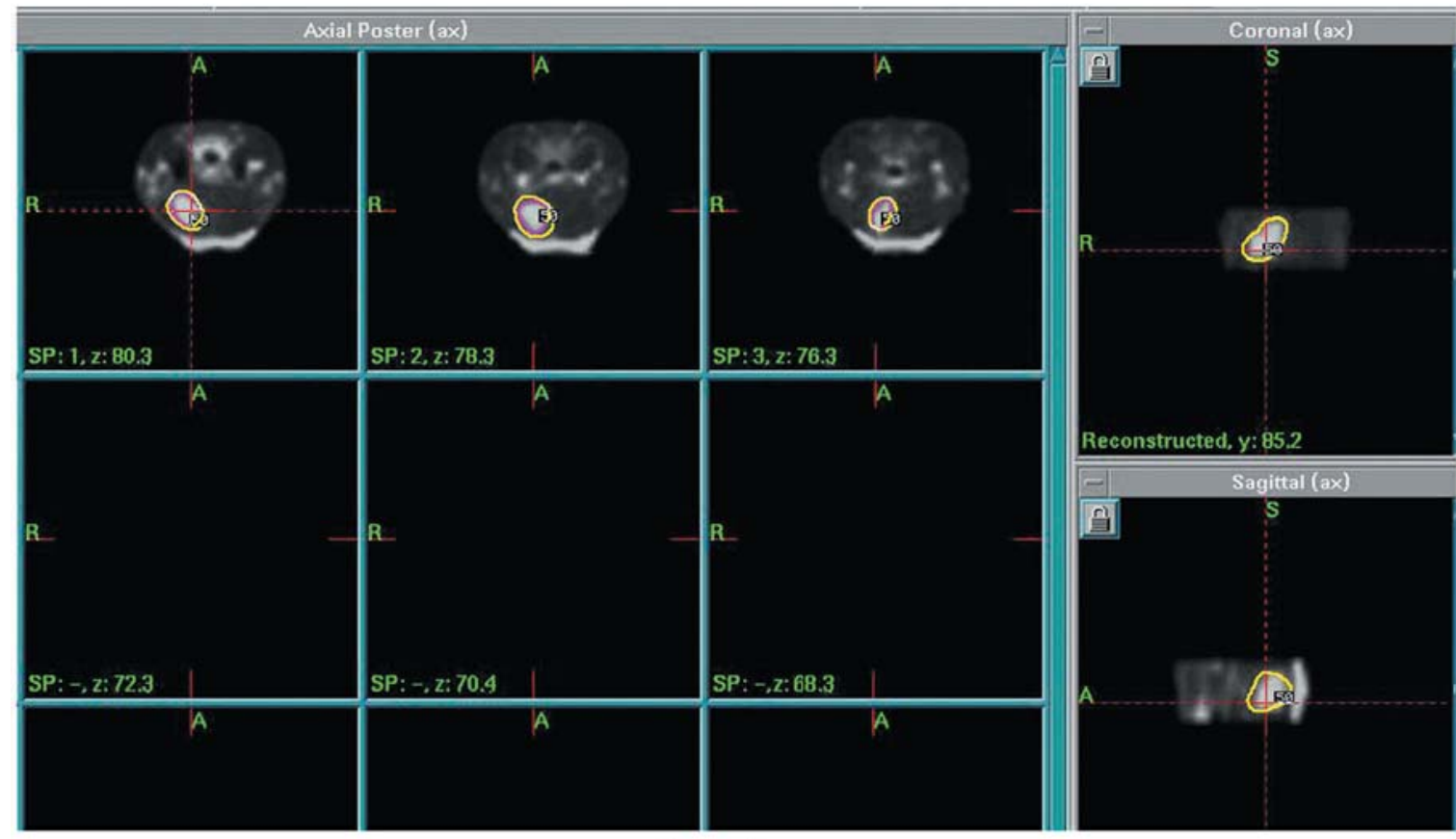

in vivo

Figure 1. Leksell Gamma Plan (version 5.31) was used to design a conformal treatment plan in vitro and in vivo.

\section{Results}

Down-regulation of EGFR expression by antisense EGFR. In order to efficiently and stably knock down EGFR expression in glioma cells, antisense EGFR expression plasmids (pantiEGFR) were transfected into C6 and TJ905 cells. After selection for 2 weeks, G418 resistant cell pools were obtained and cell lysates were analyzed by Western blot analysis. As shown in Fig. 2, antisense EGFR triggered a marked decrease in the protein levels for the target proteins both in C6 and TJ905 cells, with minimal effect on the expression of $\beta$-actin.
These results indicated that antisense EGFR potently and specifically down-regulated EGFR protein expression in glioma cells.

Effects of GKR and antisense EGFR on glioma cell proliferation and apoptosis in vitro. To evaluate the impact of GKR and antisense EGFR on glioma cell proliferation in vitro, MTT assay was measured. As shown in Fig. 3A, statistically significant cell proliferation inhibition of C6 and TJ905 cells was found in As-EGFR, GKR and combined groups compared with control group for 2 days after GKR. The growth 


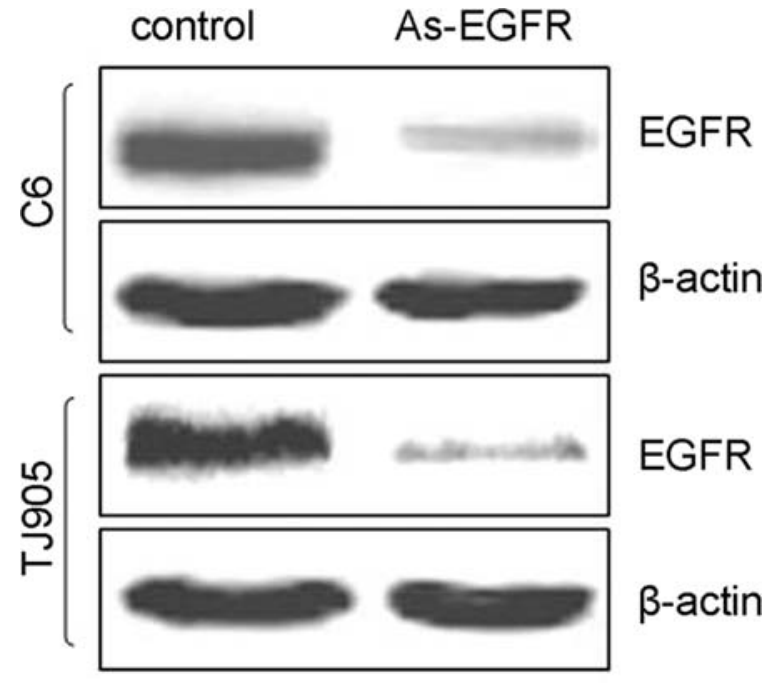

Figure 2. Antisense EGFR down-regulates EGFR expression in glioma cells. EGFR expression in C6 and TJ905 cells transfected with panti-EGFR was determined by Western blot analysis. The quantitative data show relative protein levels of EGFR (normalized to ß-actin level). rate of cells in combined group was the lowest among all four groups. There was no difference between the As-EGFR and GKR group in the experiments. Additionally, using PCNA as a biomarker for cell proliferation, we examined the effect of GKR and antisense EGFR on glioma cell proliferation in vitro by observing PCNA immunohistochemical staining. The PCNA positive rate was $86.78 \pm 4.41$, $59.35 \pm 3.79,50.71 \pm 2.61$ and $29.01 \pm 1.87 \%$, respectively for control, As-EGFR, GKR and combined group $(\mathrm{P}<0.01)$. Similar trend of cell proliferation inhibition was also detected in TJ905 cells (Fig. 3B). These results suggest that GKR combined with antisense EGFR may more effectively inhibit glioma cell proliferation than treatment with either of them.

Next, we determined the biological function of GKR and antisense EGFR on cell apoptosis of glioma cells. TUNEL staining showed that average AI of C6 cells was $0.60 \pm 0.26$, $12.73 \pm 0.48,18.39 \pm 1.06$ and $28.38 \pm 1.20 \%$, respectively for control, As-EGFR, GKR, and combined group $(\mathrm{P}<0.01)$. The apoptosis rate of TJ905 cells was also induced significantly following treatment with GKR and antisense EGFR (Fig. 3C).
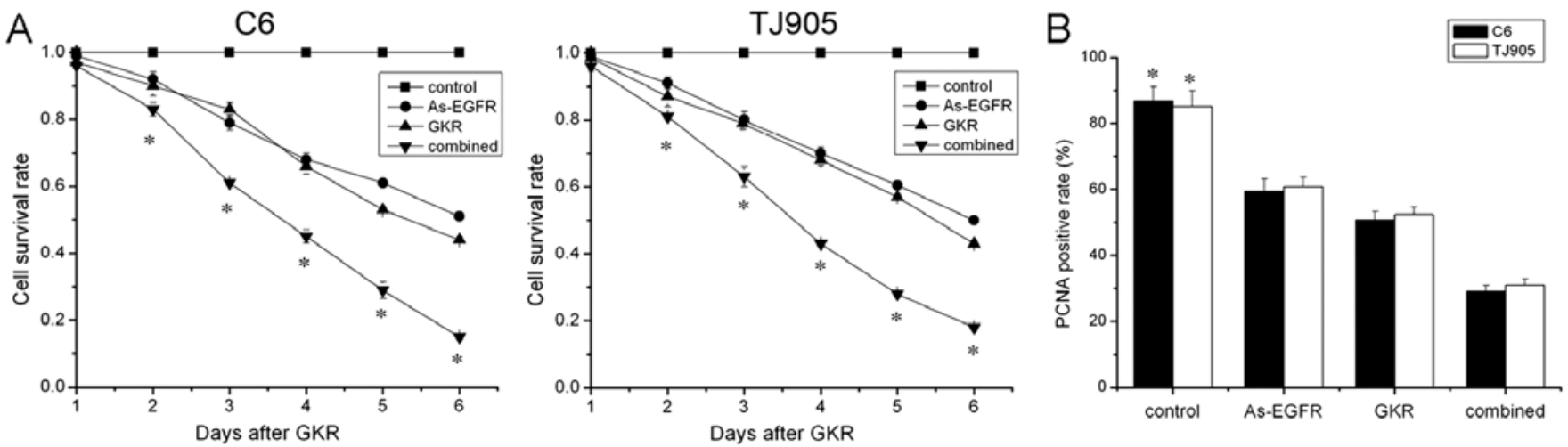

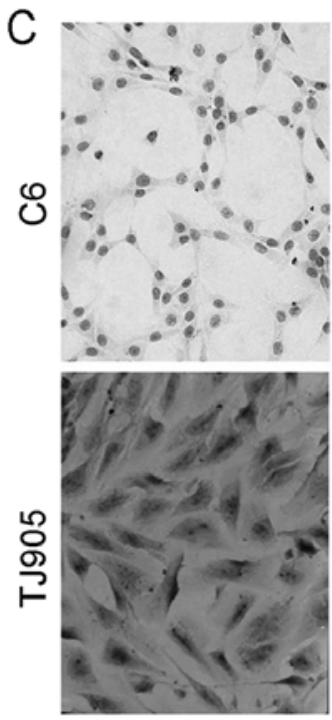

control

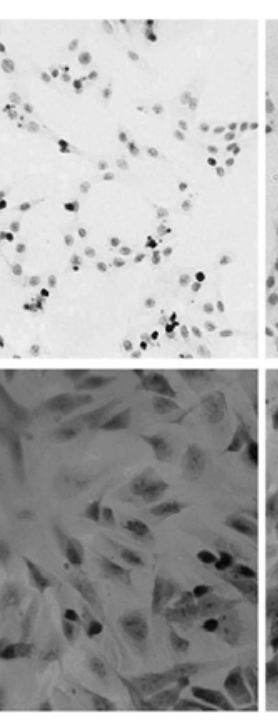

As-EGFR

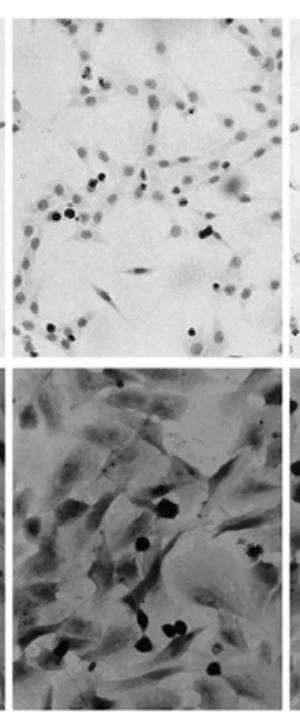

GKR

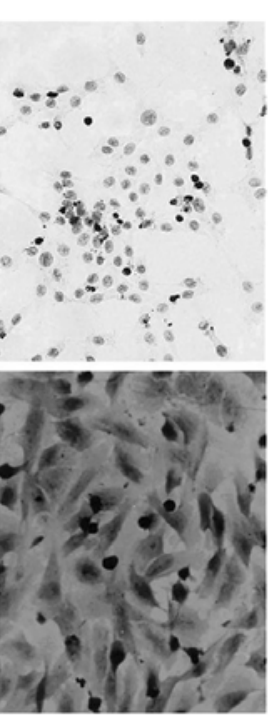

combined

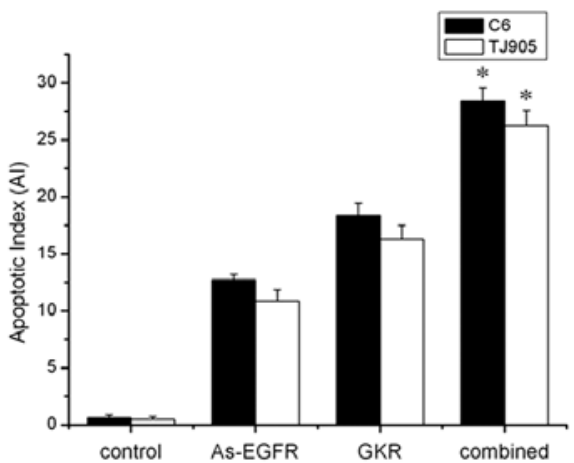

Figure 3. GKR and antisense EGFR inhibit glioma cell proliferation and apoptosis. (A) C6 and TJ905 cells in As-EGFR, GKR and combined groups proliferate at a significantly lower rate than control cells measured by MTT assay. The survival rate of combined group has the most robust cell proliferation inhibition. (B) Similar trend of cell proliferation inhibition is observed by PCNA immunohistochemical staining. The data are calculated and presented as the mean \pm SD. (C) TUNEL staining shows that combination therapy with GKR and antisense EGFR induce significant apoptosis. Apoptotic Index (AI) is calculated and presented as the mean $\pm \mathrm{SD} .{ }^{*} \mathrm{P}<0.01$. 


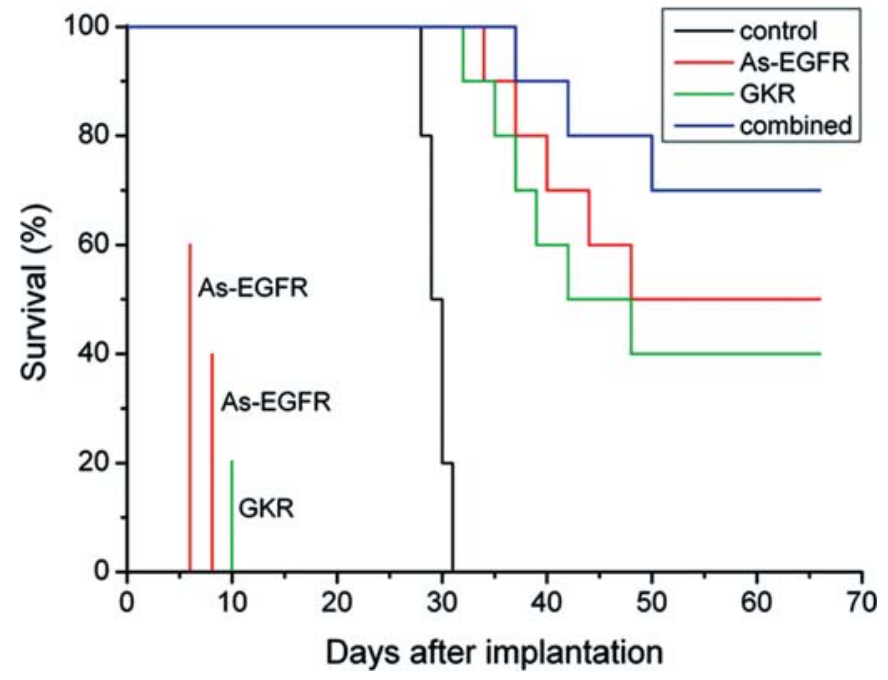

Figure 4. Graph displaying Kaplan-Meier curves for rats implanted with C6 glioma that underwent radiosurgery using $15 \mathrm{~Gy}$ to the tumour margin and antisense EGFR therapy. Rats of combined group have a longer survival time compared to the control group, As-EGFR group and GKR group $(\mathrm{P}<0.01)$

The data indicated that combination treatment with GKR and antisense EGFR had the most robust effect on cell apoptosis.

GKR and antisense EGFR prolong the survival period in vivo. Our in vitro experiments demonstrated that GKR and antisense EGFR can efficiently inhibit cell proliferation and induce apoptosis of glioma cells. Therefore, we further investigated the antitumor effect of such approaches in vivo using a C6 intracerebral tumors model. Intracerebral gliomas were well-established on day 6 post-implantation, plasmids panti-EGFR were injected into the tumor site on day 6 and 8 post-implantation, and GKR was performed on day 10 postimplantation. All surviving rats underwent MRI scan to allow for observation of tumor changes at 1,2 and 8 weeks after GKR. Figs. 4 and 5 revealed that all the rats in control group died of tumor progression, and the median survival time of these rats was 17.5 days. Five rats in As-EGFR group died on day $22,25,28,32$ and 36 , respectively, and the other 5 rats survived over 66 days after implantation (the end of observation period). In GKR group, 4 rats had prolonged survival of more than 66 days after implantation. In combined group, 7 rats were alive at the end of observation period, with no visible brain tumors by MRI scan at 8 weeks after GKR. The other 3 animals died on day 25, 30 and 38, respectively. The results suggested that rats of the combined group had a longer survival time compared to the control group, As-EGFR group and GKR group.

Two days after GKR, the tumor samples were taken out and paraffin-embedded section were prepared for proliferation (PCNA) and apoptosis (TUNEL) examination. Representative sections in the control group, As-EGFR group, GKR group and combined group are shown in Fig. 6. The expression of PCNA was greatly reduced in tumor tissues derived from the combined group, compared with that in control, As-EGFR and GKR groups $(\mathrm{P}<0.01)$. TUNEL staining showed that there were nearly no apoptotic cells found in control group. However, apoptosis was prominently increased
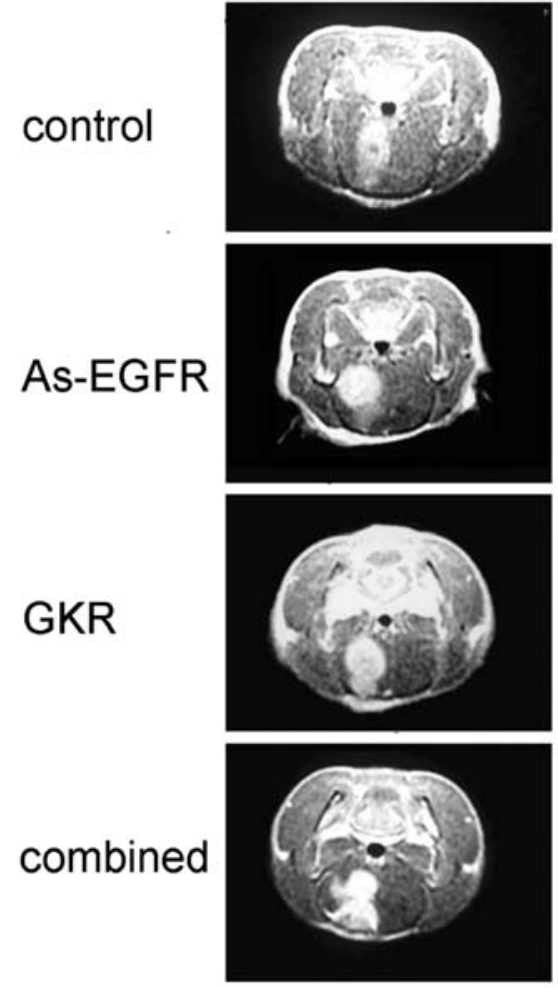

pre-GKR
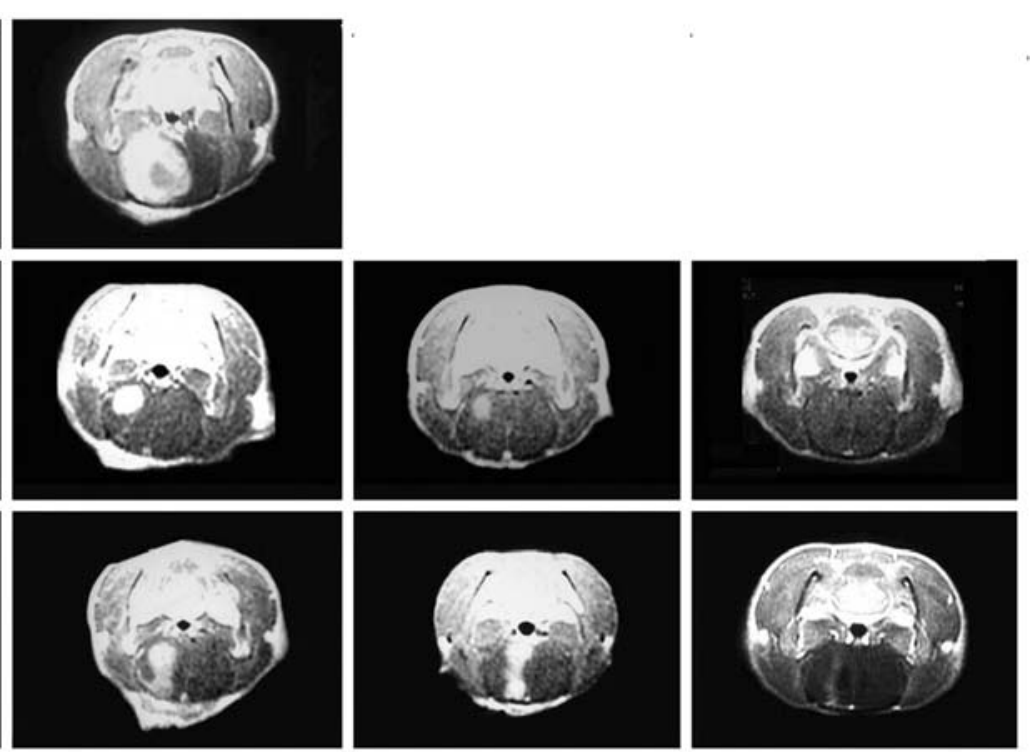

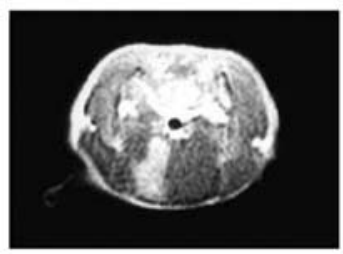

1 week

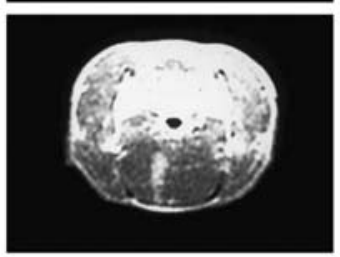

2 week

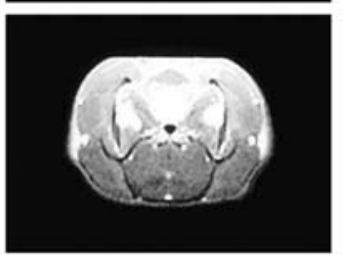

8 week

Figure 5. Dynamic MRI of glioma in orthotopic xenografts. The tumor formation in orthotopic xenografts demonstrated in MRI on day 6 post-implantation. After GKR and antisense EGFR treatment, MRI was observed until 8 weeks post-radiosurgery. 


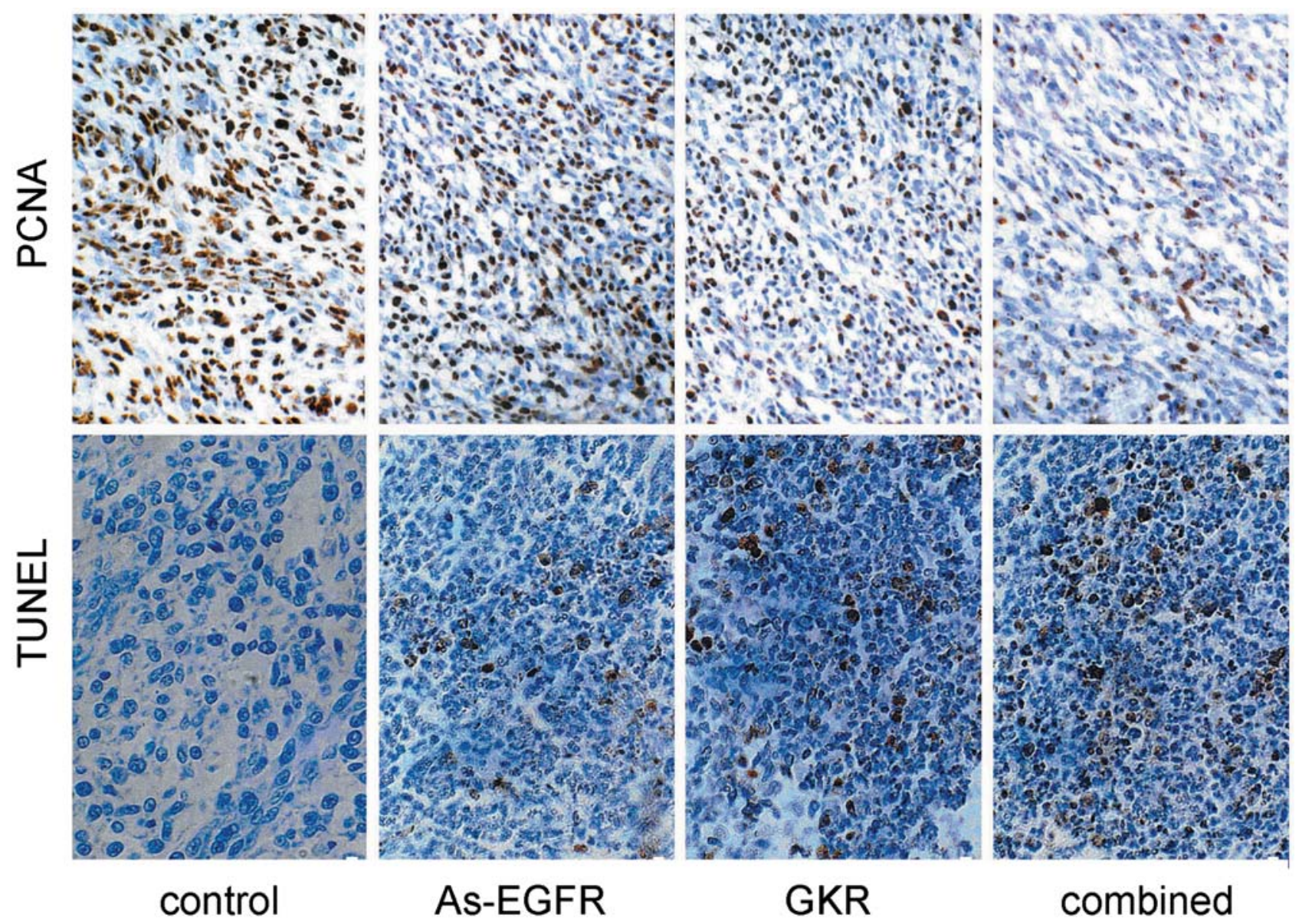

Figure 6. Immunohistochemistry analysis of tumors after treatment. Cell proliferation and apoptosis were examined by PCNA and TUNEL assay in rats bearing C6 glioma, respectively.

in the As-EGFR and GKR groups, but mostly aggregated in combined group $(\mathrm{P}<0.01)$.

\section{Discussion}

GKR is an effective method to a selected group of patients with small to medium sized, well defined, histologically proven low grade cerebral gliomas. GKR is a minimally invasive technique designed to produce a destructive radiobiological response within an imaging-defined target volume in a single session. It is capable of delivering a high dose of radiation to the tumor site with a sharp dose fall off to normal surrounding tissue. It has been demonstrated that GKR may prolong the survival period of tumor-harboring animals by inducing apoptosis and inhibiting proliferation and the cell cycle (15). The results of GKR against the $9 \mathrm{~L}$ glioma in vivo revealed that apoptosis was initially induced following radiosurgery at $\sim 6 \mathrm{~h}$, peaked $\sim 48 \mathrm{~h}$, and returned to baseline levels by $72 \mathrm{~h}$.

In our study, TUNEL staining showed that apoptosis was significantly increased $48 \mathrm{~h}$ after GKR. Although GKR can effectively kill the malignant glioma cells in the target area and prevent tumor growth, it can not control the growth of the tumor cells outside the target area or prevent the recurrence of the tumor (16). Tumor cells infiltrating into the surrounding normal brain tissue, cannot be targeted by radiosurgery for fear of causing additional neurological damage. Thus, combination therapy is the hot spot in the radiotherapy research. Our previouse study found that GKR in combination with adenoviral p53 can improve antiglioma efficacy (14).

The EGFR pathway is frequently up-regulated in highgrade gliomas via gene amplification and specific mutations. Dysregulation of EGFR-mediated signaling pathways contribute to tumor development and progression. EGFR and its ligands, activate intracellular signaling pathways, including RAS/MAPK, PI3K/AKT, and STAT-3 signal transduction pathways. The stimulation of these downstream signal pathways contribute to promote the malignant phenotype of cells, such as proliferation, anti-apoptosis, invasion, metastasis and angiogenesis $(6,17,19)$. In LN229 and U87 glioma cells, blockade of EGFR inhibits the proliferation through induction of $\mathrm{G} 1$ arrest, and this process correlates with inhibition of PI3K/Akt/mTor signaling pathway (19).

Extensive evidence indicates that EGFR signaling plays a critical role in mediating radiation resistance in human gliomas. EGFR overexpression correlates with relative resistance to radiation therapy in malignant glioma (3). Moreover, several studies have demonstrated that ionizing radiation exposure induces EGFR autophosphorylation and increases EGFR expression, and this radiation-inducible activation of EGFR may contribue to radiation resistance of tumors including cell cycle alteration, decreased apoptosis, 
and enhanced proliferation and DNA damage repair $(5,20)$. The combination EGFR blockage with radiation therapy has been evaluated by multiple laboratories. Inhibition of EGFR signaling in combination with radiotherapy has been studied with small molecule inhibitors that target the kinase domain $(21,22)$, and through gene therapy using an EGFR deletion mutant (EGFR-CD533) (23). Although each strategy has a different mechanism of action, all have shown promise in preclinical studies. However, studies on combination therapy with GKR and down-regulation of EGFR expression for glioma have not been reported.

In the present study, we demonstrated that C6 and TJ905 cells of GKR in combination with antisense EGFR showed much more decreased proliferation activity than that detected by MTT and PCNA assay in vitro of either of them. Simultaneously, the cell apoptosis increased following the combined group as examined by TUNEL method. Furthermore, the survival time of rats in the combined treatment were more prolonged in the orthotopic xenografts glioma model, consistent with dynamic MRI of glioma in orthotopic xenografts. Therefore, disruption of EGFR signaling could increase the sensitivity of glioma cells to death by GKR.

Collectively, the combined GKR and antisense EGFR treatment were more effective than treatment with either of them in vivo and in orthotopic xenografts. Our data support the potential for down-regulation of EGFR expression to enhance the radiosensitivity of glioma. However, the further mechanism is not clear and still under investigation. The findings of this study suggest that GKR in combination with EGFR-based therapy may be superior to single modality treatment of malignant glioma and provides an effective approach for glioma therapy.

\section{Acknowledgements}

This work is supported by Natural Science Foundation of Tianjin, Grant no. 05YFJMJC03600, a Program for New Century Excellent Talents in University (NCET-07-0615), Tianjin Medical University Grant no. 2006ky32 and Health Bureau Foundation of Tianjin Grant no. 09KZ91.

\section{References}

1. Salcman M: Survival in glioblastoma: Historical perspective. Neurosurgery 7: 435-439, 1980

2. Crowley RW, Pouratian N and Sheehan JP: Gamma knife surgery for glioblastoma multiforme. Neurosurg Focus 20: E17, 2006.

3. Barker FG II, Simmons ML, Chang SM, Prados MD, Larson DA, Sneed PK, Wara WM, Berger MS, Chen P, Israel MA and Aldape KD: EGFR overexpression and radiation response in glioblastoma multiforme. Int J Radiat Oncol Biol Phys 51: 410-418, 2001

4. Lammering G, Hewit TH, Valerie K, Contessa JN, Amorino GP, Dent P and Schmidt-Ullrich RK: EGFRvIII-mediated radioresistance through a strong cytoprotective response. Oncogene 22: 5545-5553, 2003.

5. Goldkorn T, Balaban N, Shannon M and Matsukuma K: EGF receptor phosphorylation is affected by ionizing radiation. Biochim Biophys Acta 1358: 289-299, 1997.
6. Mendelsohn $\mathrm{J}$ and Baselga $\mathrm{J}$ : The EGF receptor family as targets for cancer therapy. Oncogene 19: 6550-6665, 2000.

7. Liu XW, Pu PY and Gao ZX: Study on the expression of epidermal growth factor receptor gene in human gliomas. Chin J Neurosurg 14: 71-74, 1998.

8. Kang CS, Zhang ZY, Jia ZF, Wang GX, Qiu MZ, Zhou HX, $\mathrm{Yu}$ SZ, Chang J, Jiang $\mathrm{H}$ and Pu PY: Suppression of EGFR expression by antisense or small interference RNA inhibits U251 glioma cell growth in vitro and in vivo. Cancer Gene Ther 13: 530-538, 2006

9. Kang CS, Pu PY, Li YH, Zhang ZY, Qiu MZ, Huang Q and Wang GX: An in vitro study on the suppressive effect of glioma cell growth induced by plasmid-based small interference RNA (siRNA) targeting human epidermal growth factor receptor. J Neurooncol 74: 267-273, 2005.

10. Pu P, Liu X, Liu A, Cui JL and Zhang YT: Inhibitory effects of antisense epidermal growth factor receptor RNA on the proliferation of rat $\mathrm{C} 6$ gliom cells in vitro and in vivo. J Neurosurg 92: 132-139, 2000

11. Griffero F, Daga A, Marubbi D, Capra MC, Melotti A Pattarozzi A, Gatti M, Bajetto A, Porcile C, Barbieri F, Favoni RE, Lo Casto M, Zona G, Spaziante R, Florio T and Corte G: Different response of human glioma tumor-initiating cells to epidermal growth factor receptor kinase inhibitors. J Biol Chem 284: 7138-7148, 2009.

12. You Y, Pu P, Huang Q, Xia Z, Wang C, Wang G, Yu C, Yu JJ, Reed E and Li QQ: Antisense telomerase RNA inhibits the growth of human glioma cells in vitro and in vivo. Int J Oncol 28: $1225-1232,2006$

13. Moroni MC, Willingham MC and Beguinot L: EGFR antisense RNA blocks expression of epidermal growth factor receptor and suppresses the transforming phenotype of a human carcinoma cell line. J Biol Chem 267: 2714-2722, 1992.

14. Xu D, Jia Q, Li Y, Kang C and Pu P: Effects of Gamma Knife surgery on C6 glioma in combination with adenoviral p53 in vitro and in vivo. J Neurosurg 105: S208-S213. 2006.

15. Witham TF, Okada H, Fellows W, Hamilton RL, Flickinger JC, Chambers WH, Pollack IF, Watkins SC and Kondziolka D: The characterization of tumor apoptosis after experimental radiosurgery. Stereotact Funct Neurosurg 83: 17-24, 2005.

16. Yu X, Liu ZH, Zhou DX, Hao JM, Du JX, Zhang W and Li B: The clinical preliminary report of Gamma knife radiosurgery for gliomas. Chin J Neurosurg 18: 83-86, 2002.

17. Lal A, Glazer CA, Martinson HM, Friedman HS, Archer GE, Sampson JH and Riggins GJ: Mutant epidermal growth factor receptor up-regulates molecular effectors of tumor invasion. Cancer Res 62: 3335-3339, 2002

18. Wells A: EGF receptor. Int J Biochem Cell 31: 637-643, 1999.

19. Fan QW, Cheng CK, Nicolaides TP, Hackett CS, Knight ZA, Shokat KM and Weiss WA: A dual PI3K $\alpha /$ mTOR inhibitor cooperates with blockade of EGFR in PTEN-mutant glioma. Cancer Res 67: 7960-7965, 2007.

20. Dent P, Reardon DB, Park JS, Bowers G, Logsdon C, Valerie K and Schmidt-Ullrich R: Radiation-induced release of transforming growth factor- $\alpha$ activates the epidermal growth factor receptor and mitogen-activated protein kinase pathway in carcinoma cells, leading to increased proliferation and protection from radiation-induced cell death. Mol Biol Cell 10: 2493-2506, 1999.

21. Huang SM, Li J, Armstrong EA and Harari PM: Modulation of radiation response and tumor-induced angiogenesis after epidermal growth factor receptor inhibition by ZD1839 (Iressa). Cancer Res 62: 4300-4306, 2002

22. Shintani S, Li C, Mihara M, Terakado N, Yano J, Nakashiro K and Hamakawa $\mathrm{H}$ : Enhancement of tumor radioresponse by combined treatment with gefitinib (Iressa, ZD1839), an epidermal growth factor receptor tyrosine kinase inhibitor, is accompanied by inhibition of DNA damage repair and cell growth in oral cancer. Int J Cancer 107: 1030-1037, 2003.

23. Contessa JN, Reardon DB, Todd D, Dent P, Mikkelsen RB, Valerie K, Bowers GD and Schmidt-Ullrich RK: The inducible expression of dominant-negative epidermal growth factor receptor-CD533 results in radiosensitization of human mammary carcinoma cells. Clin Cancer Res 5: 405-411, 1999. 